\title{
Nursing in Saudi Arabia: Reflections on the experiences of SOUTH African NURSES
}

\section{Authors:}

Dalena van Rooyen Colette D. Telford-Smith ${ }^{2}$ Johanita Strümpher

\section{Affiliations:}

'Department of Nursing Science, Nelson Mandela Metropolitan University, Port Elizabeth, South Africa

${ }^{2}$ King Faisal Specialist Hospital and Research Centre, Riyadh, Saudi Arabia

\section{Correspondence to:} Dalena van Rooyen

email:

dalena.vanrooyen@nmmu. ac.za

\section{Postal address:}

Department of Nursing Science, Nelson Mandela Metropolitan University, PO Box 77000,

Port Elizabeth 6031 South Africa

\section{Keywords:} nursing; cultural diversity; lived experience; South Africa; Saudi Arabia

Dates:

Received: 29 Apr. 2008 Accepted: 23 Sept. 2009 Published: 17 Mar. 2010

How to cite this article: Van Rooyen, D., TelfordSmith, C.D. \& Strümpher, J., 2010, 'Nursing in Saudi Arabia: Reflections on the experiences of South African nurses', Health SA Gesondheid 15(1), Art. \#500, 9 pages. DOI: $10.4102 /$ hsag.v15i1.500

This article is available http:/ /www.hsag.co.za

(c) 2010. The Authors. Licensee: OpenJournals Publishing. This work is licensed under the Creative Commons Attribution License.

\section{ABSTRACT}

The purpose of the study was to describe and reflect on the lived experiences of the South African nurses residing and working in the Kingdom of Saudi Arabia. A qualitative, exploratory, descriptive and contextual design with a phenomenological approach was adopted. Data were collected by means of individual interviews and the personal journals of the nurses who met the sampling criteria. The data analysis was done according to Tesch's descriptive method (in Creswell 1994). The main theme that emerged was one of 'cultural diversity'. Sub-themes related to the nurses' religious/spiritual, environmental, emotional/psychological and professional experiences were also identified. A literature control was undertaken to verify the results. Limitations were highlighted, conclusions were drawn and recommendations relating to nursing research, education and practice were made.

\section{OPSOMMING}

Die doel van die studie was om die lewenservarings van Suid-Afrikaanse verpleegkundiges wat in die Koningkryk van Saoedi-Arabië werksaam en woonagtig is, te beskryf en daaroor te besin. 'n Kwalitatiewe, verkennende, beskrywende en kontekstuele navorsingsontwerp of strategie van ondersoek, vanuit 'n fenomenologiese benadering, is vir die doel ingespan. Data is ingesamel aan die hand van individuele onderhoude met deelnemers wat aan die kriteria vir insluiting by die steekproef voldoen het en persoonlike joernale wat deur hierdie deelnemers bygehou is. Dataontleding is volgens die beskrywende metode van Tesch (in Creswell 1994) gedoen. Die hooftema voortspruitend uit die navorsing was dieé van 'kulturele diversiteit'. Verdere temas ten opsigte van verpleegkundiges se godsdienstige/geestelike, omgewings-, emosionele/psigiese en professionele ervarings is ook geïdentifiseer. ' $n$ Literatuurkontrole is onderneem om die navorsingsbevindinge te verifieer. Beperkings is uitgelig, en gevolgtrekkings en aanbevelings gerig op verpleegkundige navorsing, onderrig en praktyk is gemaak.

\section{INTRODUCTION}

\section{Background}

The greatest political challenge to nursing today is the shortage of nurses worldwide and the migration of nurses from one country to another (Hancock 2001:19). A study, conducted by the International Council for Nurses (ICN) (2003:137) on international nurse mobilisation, trends and policy implications, states that there are certain push and pull factors that drive nurse migration. Pull factors are evident in destination countries that have failed to grow and keep their own nurses in sufficient numbers. These destination countries therefore use the 'quick fix' of international recruiting by exploiting the existence of push factors, such as low pay, poor working conditions, lack of resources, limited career and educational opportunities, economic instability and unstable and dangerous work environments, as well as by emphasising the pull factors of better working conditions, salaries and career opportunities, resourced health systems, political stability and travel opportunities to fuel the phenomenon of nurse migration (International Council for Nurses 2003:137).

The study conducted by the ICN (2003:137) points to the fact that nurses (throughout the world) migrate in search of incentives that fall within three categories, which are (1) improved learning and practice opportunities, (2) better quality of life, pay and working conditions, and (3) personal safety (International Council for Nurses 2003:137).

There are, however, consequences to international nurse migration:

- It impacts negatively on the national health system of every 'exporting' country (Kaplan, Brown \& Meyer 1999:1; Thompson 2003:1).

- It impacts on the families that are left behind. With the departure of one of the key role players there is a danger of the family unit becoming fragmented and the daily routine disrupted (International Council for Nurses 2001:3; Itano 2002:1; Naidoo 2000:1).

- It exposes the individual nurse to potential dangers and vulnerabilities (International Council for Nurses 2002:10).

Regardless of where or how nurses choose to work, though, the workplace environment plays a vital role in the nature of the practice and on its outcomes on both the providers and recipients of care. It is every nurse's right to work in an optimal environment and this also ensures quality nursing. It is also the duty of every nurse leader to transform the practice environment so that the essence, uniqueness and outcomes of professional practice will be realised (Van der Merwe 2003:5).

\section{PROBLEM STATEMENT}

South Africa has experienced an exodus of skilled professionals over the last decade and the past five years have witnessed an increased number of health professionals leaving South Africa for 'greener 
pastures' (Itano 2002:1). According to the World Health Organization (WHO) (in Mafalo 2003:39), this migration can be attributed to low pay, poor working conditions and failure to recognise the value of nurses and the importance of providing them with attractive career prospects.

The Kingdom of Saudi Arabia (KSA) is one of the more popular destinations for South African nurses, as the financial rewards there are excellent. Here nurses can earn an annual tax-free salary of approximately R228 000.00 to R360 000.00 (South African Rand), compared to an annual salary (after four years of training) of approximately R75 400.00 in South Africa (Republic of South Africa 2005)

In order to provide a point of departure for understanding the participants' experiences, it is necessary to briefly describe aspects of Saudi Arabian culture.

\section{Aspects of Saudi Arabian culture}

The KSA hosts a diversity of cultures, but there mainly appear to be parallel systems that create two vastly different lifestyles: that of the Bedouin, who are desert dwellers, and that of the modern KSA, which embraces, incorporates and accepts all contemporary luxuries.

There are two different calendars, the Gregorian and the Hijrah, with the latter being the official Islamic calendar. This calendar has twelve lunar months, the beginnings and endings of which are determined by the sighting of the crescent moon. Weekends are Thursdays and Fridays (Huda 2005). Friday is reserved for public executions and the amputation of digits and limbs is an accepted and practiced form of punishment. This practice was very foreign to the nursing participants and instilled feelings of fear and horror.

Islam is the only religion tolerated in the KSA. The Muttawaan (religious police) have a presence in both the professional and social environments. They impose strict codes of morality on the Saudi population, which are further extended to Westerners. They have the power to arrest any unrelated/unmarried men and women caught socialising and to ban consumer products and media (Wikipedia.org 2005).

Women in the KSA have a restricted role in public life, with few political rights and are not treated as equal members of society. Life for women in the KSA is arguably more difficult than in other countries in the world, particularly with regard to freedom of movement (they are forbidden to drive and may not travel without being accompanied by a male relative), speech and dress (Ham 2004:37).

Besides the monetary incentives referred to above, the personal experience and observations of one of the authors is that it is a stressful experience for South African nurses to leave their families and travel abroad for employment opportunities in the KSA. Even if the travel and change in work situation are planned, culture shock is prevalent from the moment they step off the plane. For the South African nurse, this includes the shock of being separated from loved ones, support systems, and familiar sights, sounds and smells. Furthermore, the shock includes being in a Muslim country, where strict adherence to orthodox tenets and traditions is practiced and where the language is unfamiliar. In view of the fact that it is not known how (South African) nurses experience working in foreign countries, the focus of this research study was to explore and describe the lived experiences of South African nurses who had migrated to pursue nursing careers in the Kingdom of Saudi Arabia.

\section{RESEARCH QUESTION}

The question to be answered by this research endeavour was the following: 'What are the professional and personal experiences of the South African nurses working and living in Saudi Arabia?'

\section{Objectives}

In order to answer the aforementioned research question, two objectives were formulated, namely:

- To explore and describe the lived experiences of South African nurses related to living and working in the KSA (primary objective).

- To make recommendations directed at nursing research, education and practice to aid the phenomenon of migration of South African nurses working and living in the KSA (secondary objective).

\section{RESEARCH DESIGN AND METHOD}

The researchers chose a qualitative, exploratory, descriptive and contextual research design, or strategy of inquiry from a phenomenological approach, in order to reflect upon the experiences of South African nurses living and working in the KSA. Phenomenology seeks to understand the lived experience of individuals. It is a search for 'essence' and aims to answer the question, 'What is it like to have a certain experience?' (Crabtree \& Miller 1999:28)

\section{Population and sampling}

From the target population, comprising all SA nurses living and working in the KSA, a purposive sample was drawn, as the researchers sought participants because of their knowledge and ability to describe the phenomenon under study (Donalek \& Soldwisch 2004:356). Only participants who met the following six criteria were included, these were:

- Being registered as nurses (and having current registration with the South African Nursing Council).

- Being English- or Afrikaans-speaking, as these were the languages with which the researcher was familiar.

- Being representative of different gender groups.

- Being representative of various cultural groupings according to the South African cultural profile.

- Having resided in Saudi Arabia for a period of three to six months (these nurses have enough experience to maintain a viewpoint, but have not become too immersed in their situation, for a person could gain experience of living in the KSA in three months, but, after six months, may have grown used to the changes in lifestyle).

- Having indicated their marital status as 'single', 'married' or 'divorced'.

\section{Data collection}

The researcher/fieldworker made use of unstructured phenomenological interviews as the main method of data collection. The participants were interviewed in their private quarters when they were off duty. The researcher adhered to phenomenological interviewing techniques, as described by Kvale (1996:149). Field notes and the participants' personal journals further served as methods for data collection. Personal journals (Polit \& Hungler 1997:254-256) were kept for 10 days after the interview. The information was integrated when the final themes were identified.

The following general opening question was posed to the participants: 'What are your experiences with regard to living and working in Saudi Arabia?' Then the following sub-question was directed to the participants: 'How can a registered nurse be assisted to function effectively in Saudi Arabia?' Eleven indepth phenomenological interviews, each lasting between 45 and $60 \mathrm{~min}$, were conducted, after which 'data saturation' was achieved, in that the themes that emerged became recurrent (Donalek \& Soldwisch 2004:356).

\section{Data analysis}

Data analysis can be described as 'a search for patterns in datarecurrent behaviours, objects or a body of knowledge' (Neuman 
1994:426). The recorded interviews were transcribed and analysed, along with the field notes and personal journals. The data were analysed using a thematic analysis approach based on the eight steps proposed by Tesch (in Creswell 1994:154-155). According to the principles of phenomenological research, the researcher made use of intuiting, bracketing, analysing the data and describing the results (Polit \& Hungler 1993:328)

\section{TRUSTWORTHINESS}

Guba's model of trustworthiness (in Krefting 1991:214) was utilised to ensure the trustworthiness of this research endeavour. Guba's model is based on the identification of four aspects of trustworthiness, namely:

\section{Truth value}

Truth value is based on the criterion of 'credibility'. This refers to the findings of the study being based on the discovery of human experience as it was experienced and observed by the participants. The particular actions taken to achieve credibility included prolonged engagement, reflexivity, triangulation (of data and literature sources), peer examination, interviewing techniques, structural coherence, and the authority of the researcher/fieldworker.

\section{Applicability}

This describes the extent to which the findings could be implemented in different contexts and with other groups. 'Transferability' is the criterion against which applicability is assessed. The purpose of this study, as with other qualitative studies, was not to generalise the findings, but rather to gain an in-depth understanding of the research phenomenon. Transferability was achieved by drawing a nominated sample, by documenting a dense description of the research methodology and by working contextually so that procedures could be duplicated accurately.

\section{Consistency}

Consistency is concerned with the extent to which the replication of the study in a similar context and with the same participants will produce the same results. 'Dependability' was the criterion used to ensure consistency. The strategies that were taken to ensure dependability in this case included a dense description of the research methodology employed, the triangulation of data sources, and peer examination.

\section{Neutrality}

This refers to there being no evidence of prejudice in the research procedure and research results. 'Confirmability' is the criterion against which neutrality is measured. This refers to whether the results attained from the research can be confirmed by another. It places the focus on the evaluation of the data. Strategies used in this study to ensure neutrality were a confirmability audit, triangulation, and reflexivity.

\section{ETHICAL CONSIDERATIONS}

For the purpose of this research, the ethical standards established by the Democratic Nursing Organisation of South Africa (1998:2.2.1-2.3.4) for nursing practice and research were adhered to, with specific reference to the following:

- Every effort was taken not to expose participants to any harm or exploitation.

- Informed consent was obtained once all the information relating to the research project and what it entailed had been given to the participants before they partook in the research endeavour, and it was emphasised that participation was voluntary and that they could withdraw at any time.

- The anonymity of the participants was guaranteed, their privacy was respected and they were assured that the information shared would be treated confidentially.

\section{DISCUSSION}

Cultural diversity was found to be the common thread that ran through the central and sub-themes.

\section{Central theme: Cultural diversity is encountered in all aspects of the nurses' lives while living and working in Saudi Arabia}

The participants had previously encountered Muslims in South Africa in both their personal and professional lives. Many of the participants expected that their prior exposure and experiences within the context of South African Muslim communities would assist them in facing the challenges and diversities awaiting them on arrival in the KSA. As the study unfolded, though, it became evident that the participants had been misguided by their preconceived ideas, as indicated by the following statements:

'To me, the living with the Muslim culture is fine because I come from Cape Town and was brought up in a small Muslim environment ... but it was [still] like a shock."

'I tried to prepare myself as best I could, but no amount of preparation could have readied me for what awaited.

The central theme, cultural diversity, which was encountered in all aspects of their lives by the participants as South African nurses while living and working in Saudi Arabia, will be divided into sub-themes in the next section of the paper. Culture can be defined as the customary beliefs, values and ideas held by a group of people. It affects the individual's way of living because a culture's customs are passed on from one generation to the next. Individuals learn the customs through communicating with like-minded individuals (Waughfield 2002:430). Diversity indicates the differences amongst a group, as well as how people from different backgrounds have different customs. According to Ross and Deverell (2004:25), different cultures assign different meanings to health and wellness and how to act when feeling unwell.

\section{Sub-theme 1: The participants' religious/spiritual experiences}

The Islamic religion is an all-encompassing way of life that permeates all aspects of the Saudi Arabian culture (Ham 2004:33).

\section{The practice of Ramadan}

The ninth month of the Muslim calendar is Ramadan, a period of obligatory fasting that commemorates the Prophet Muhammad's receipt of God's revelation, the Quran. Out of respect to the Muslim population who are fasting, non-Muslims are not allowed to eat and drink in public places, even to the extent of having to place a water bottle in a paper bag when walking down the hospital corridor. The participants, even though respectful, experienced feelings of discrimination and unfairness, and even presented with the effects of dehydration.

'Fasting in Ramadan ... Westerners are not allowed to and drink anything in front of them ... caused headaches because of being deprived of fluids.

During Ramadan, Muslim staff members are only required to work 72 of the prescribed 88 hours in two weeks of regular shifts. Of these 72 hours, they are required to work a maximum of six hours per shift. This means that the non-Muslim staff members are required to cover for the Muslim staff during the hours they have been given off, adding an additional load to their already heavy assignments. The participants accepted this religious practice, but described working under these circumstances as 'frustrating' and said that they were 'exhausted'.

\section{Prayer times}

The Muslim believer has to perform salat in a prescribed manner, after purification through ritual ablutions, at dawn, midday, 
mid-afternoon, sunset and nightfall. During prayer times, all shops and businesses close. During the day shift at the hospital (07h00 - 19h00), the Muslim employees are called to prayer and, therefore, leave their units/departments for approximately 20 to 30 minutes, three times a day. During these times, the nonMuslim nurses are responsible for their Muslim colleagues' assignments. This evoked feelings of frustration among the participants and one participant thought it was unfair:

'... and the Arab nurse in the ward ... you must do her work while she is going to pray ... I have also got my religion, but I have got time to do it at some other time when I am off duty ... but she has to do everything here at work ... it is really unfair'.

\section{Religious intolerance}

The practice of any religion other than Islam is strictly prohibited (Ham 2004:52). This extends to bringing into the country printed religious material or other symbols. The authorities are very serious about enforcing this and the consequence of not respecting the religious law is imprisonment or deportation. The following statement by a participant refers to imprisonment for not respecting the religious law.

'Did you know there was a man arrested three weeks ago for trying to open a church... If you are going to attend church you are going to go to jail.

The participants explained that church services and Bible studies are held 'underground'. Certain codes are used for the word 'church' and, when one is going to church, one says 'I am going to a meeting', or 'I am going for coffee'. All were aware that they had constantly to be careful about the content of conversations, email, letters and telephone calls. Being Christian, the participants found that being forbidden to practise their faith was a negative experience, which invoked feelings of fear and worthlessness. The following quotations testify to this.

'And also I've been warned about this often to be very careful what you say on the telephone and be very careful what you write in e-mails.'

'You know there is a sense of worthlessness ... there is a sense of hopelessness ... there is a sense of total disrespect and disregard. It is very restricting, because basically every word that comes out of your mouth you have to watch.

It was evident that all the participants derived strength from spending time alone in religious contemplation and having the inner assurance that they were not alone. Most of the participants believed they had grown closer to God since coming to the KSA.

'I have my CD player with me and there is always a gospel $C D$ in ... it gives me strength and security to face the next day.'

According to Kniesl and Trigoboff (2009:92), using prayer and religious practices is an effective everyday way of coping with stress.

\section{Sub-theme 2: The participants' environmental experiences}

The participants in this study identified physical-political and psycho-social environmental experiences and described having to adapt to these.

\section{The physical-political environment}

The KSA extends across approximately 2149690 square kilometres, with $95 \%$ comprising desert or semi-desert. The country suffers extreme temperatures throughout the year. The heat of the desert (as well as the city) can and does reach temperatures exceeding $50^{\circ} \mathrm{C}$ (Ham 2004:40).

The participants all arrived at the King Khalid International airport in Riyadh. As they walked out of the air-conditioned terminal, the extreme heat was their first introduction to the Arabian climate. From the airport they were transported to their individual compounds. For many, the concept of compound living was as foreign as the country itself. In some ways, the compounds offered a 'world-within-a-world', a self-contained retreat from the idiosyncrasies of life in the KSA. The strong sense of community felt in many of the compounds, coupled with the other residents' wealth of knowledge, provided the soft landing the participants needed. Swimming pools, supermarkets, beauty salons, coffee shops and gyms were provided to help the transition.

The participants were accommodated in one-, two- or threebedroom flats with separate bedrooms and, for the most, separate bathrooms plus air conditioning and modern conveniences were standard. Most were pleasantly surprised at the standard of accommodation.

'I am happy about the accommodation. It is very good ... it has everything you need and I don't have to pay anything ... not a cent ... electricity is free, water is free and it is well furnished.'

The physical climate had an effect on the health of many of the participants. Clinical manifestations of dehydration, headaches and exhaustion resulted from the extreme heat to which they were exposed, as already described. Some developed skin rashes, which were attributed to the water as well as the dry and hot conditions.

[Wearing the abaya you are] covered from head to toe and whew, in 45 degrees. It is a bit much ...

Myburgh, Niehaus and Poggenpoel (2006:111) reported on a qualitative study in which $16 \mathrm{PhD}$ students studying in a host country were asked about their experiences. The respondents reported feeling disorientated, confused or spiritually displaced; they felt as if their body-clocks were out of rhythm.

The participants expressed amazement at the almost non-existent crime rate in the KSA, which is a far cry from the situation in South Africa. They experienced freedom when walking in the streets and shops, without the constant anxiety of having to 'look over their shoulder' for fear of being attacked or robbed, as they did back home:

\footnotetext{
'...from a crime perspective ... we feel free ... you can relax when you go to the shops'.
}

This was perceived as being very positive. Ham (2004:51) confirms the experiences of the participants by stating that street crime is extremely rare in Saudi Arabia.

\section{Instability of the political environment}

The unstable political environment was a source of anxiety for the participants and made them feel unsafe. As one participant said:

At times I feel very unsafe due to the whole situation in the Middle East recently ... the Iraq war and the killing of Westerners in this country ...'

Security at the compounds and places of work was generally good. Nevertheless, having to watch the security situation nervously and be willing to pack and leave at a moment's notice, had a wearing and nerve-wracking effect on many. Most of the participants, having been in the KSA for only a short period, had not reached the stage of resignation to, and acceptance of, the unstable political situation.

\section{The psycho-social environment}

Experiencing the dress code: The religion and culture of the KSA dictate conservative dress for both men and women. Expatriate men do not have to adopt the cultural dress of the Saudi men. The male participant in this study had the freedom to wear, in public, the clothes that he was accustomed to back home, with the exception of shorts and sleeveless shirts. Adaptation to a different style of dress was, therefore, of no consequence to him.

When Saudi women appear in public, they wear a voluminous black cloak called an abaya and a scarf covering their hair, 
and many have a full-face veil. All women living within the boundaries of the KSA are expected to respect the dress code of the Saudi culture, with South Africans being no exception. Although the participants were aware of the dress code prior to coming to the KSA, their experiences of actually wearing the abaya and the headscarf were varied.

'When it is hot, this becomes a burden... you must sit around and be covered from head to toe in 45 degrees heat.

'It doesn't matter what you wear under the abaya ... you can wear your pyjamas, nobody will know...'

The female participants agreed unanimously that wearing the abaya was a hindrance, especially because of the Arabian climate and the sweltering heat. One participant said:

'When it is hot... you just want to scream because this [the abaya] becomes like a burden that you are carrying on you...

The psychological impact was real for many of the participants, who had to work through the feelings of 'lack of self worth' that 'covering up' instilled. The participants eventually came to the realisation that it was important that they felt ' $o k^{\prime}$ within themselves, 'despite' having to wear the abaya. The following affirmative statement made by a participant points to this:

'Nobody really knows what you wear underneath, as long as you feel ok.'

The participants placed less emphasis on wearing a head covering, as they were not required to wear it when they left the hospital premises. They were aware that the Muttawaan could ask them to 'cover their head' at any time, but they did not expect to be verbally abused or harassed. Having only recently arrived in the KSA, they expressed feelings of fear, anger and indignation. They described wearing headscarves as hot and uncomfortable. Myburgh et al. (2006:111) also reported that the participants in their study (PhD students studying in a foreign country) reported problems with the cost of living.

Experiencing gender discrimination/segregation: Running throughout the central theme was the reality of the segregation of, and discrimination between, men and women in the KSA. The participants were exposed and subjected to this reality from the time they landed in Saudi Arabia. They had no option but to adapt and conform to this aspect of Saudi culture. Areas that had a particular impact on the participants included women being prohibited from driving and experiences while shopping, where they were served by males in clothing shops, for example. Myburgh et al. (2006:111) reported that their participants also experienced discrimination against international students with respect to travel concessions. They reported that local students seemed to resent the international students because they felt that opportunities for learning were taken from them by these foreigners.

Prohibition of women driving: All the female participants had been informed before coming to the KSA that they would not be permitted to drive. However, this paradigm shift only became a reality when they experienced this 'loss of independence', having to give way to a 'forced dependence' on alternative transportation. Participants who had not been accustomed to driving and had relied on public transport in South Africa did not place as much emphasis on this loss of independence. They focused more on the expense of taxi fares and their perceptions of the driving habits of Saudi men.

Medi-Clinic had imported a number of Indian professional nurses to work in their clinics in South Africa. They did a study to determine how well the nurses adapted to their host country. The Indian nurses reported that they would have liked to be able to travel by private car so that they did not have to make use of taxis. In their own culture the females were not supposed to sit so close to males (Medi-Clinic 2008:35).

Shopping: Shopping during off-duty time was identified as a major activity by the participants. This activity, although enjoyable, was not without frustrations. The participants had to rely on taxis to fetch them. During prayer time, they had to wait until a taxi became available, as most drivers were at prayer. They also had to contend with the closure of all shops and restaurants during prayer times. Certain shops did not allow women to frequent them. Garments were not allowed to be fitted in the shops. This had to be done at home and the garments returned to the shops if they were not suitable. This was timeconsuming, frustrating and expensive for the participants. Participants who were unaware of the prohibition against trying on garments were made to feel very uncomfortable by the male shop attendants.

Gender interaction: As a consequence of the strict segregation of the genders in the KSA, the participants observed minimal communication between men and women in public. Men and women do not shake hands and prolonged eye contact is avoided. Female nurses may provide nursing care for male patients, but male nurses are not permitted to provide direct patient care for a female patient. Housing is segregated and visiting/socialising with the opposite sex is prohibited. Social amenities, such as swimming pools and tennis courts, have separate days assigned for men and women. All the participants experienced Saudi men as disrespectful towards them.

The participants struggled to adapt to the social environment. To overcome this, those who enjoyed travel and nature went on trips offered by the hospital's social club, while others joined a social club for expatriates that organises walks or runs in the desert every weekend. The participants that were partygoers went to parties at 'mixed compounds'. (These compounds house families and single men (separately) and, as the Muttawaan have little or no jurisdiction over these compounds, social evenings are often held.) The segregation between men and women in the KSA was perceived as abnormal and evoked varied responses from the participants, including feelings of irritation, anger and boredom.

\section{Sub-theme 3: Participants' emotional/ psychological experiences}

Whenever people are immersed in another culture, they go through a period of cultural adjustment. The initial stages are the excitement or 'honeymoon' phase, culture shock and surface adjustment (Andrews \& Boyle 1995:430). Leaving home and loved ones was traumatic for the participants. One participant voiced this as follows:

'It was very traumatic [leaving the family behind] ... It was extremely traumatic ... I cried all the way ... was tearful for the first three months ... Sometimes I just felt I cold not cope at all...'

It became evident when interviewing the participants that they had exited the 'honeymoon period' and entered into the second phase - 'culture shock'. All were experiencing a 'rollercoaster' of emotions. The 'lows' ranged from sadness at being so far away from home, to loneliness and depression. The 'highs' ranged from happiness at meeting new friends, to feelings of achievement on meeting financial objectives. Experiencing the loss of a family through distance, even if it is only temporary, causes a person to mourn the loss. According to Antai-Ontong (2008:240), a grieving person may expect to experience emotions such as sadness, anxiety, anger and guilt. In trying to cope with grief, the person may experience sleep disturbances, eating disturbances, crying and social withdrawal. All these reactions were reported by the participants.

Guilt and emotional pain were emotions experienced by the participants who had left family, and more specifically children, behind. The absence of one parent had had unexpected consequences for the families of participants who were parents, which was evident through changes in the child/children's behavioural patterns. More than one participant testified to the fact that their child would not talk to them, while others reported 
that their children had become withdrawn, often refusing to eat, or they had begun stealing and that their school work had deteriorated since their parent's departure. These children were also going through their own grieving process and exhibited quite a few of the symptoms indicating anxiety and loss (AntaiOntong 2008:245).

In the workplace the 'rollercoaster' of emotions continued. The participants experienced a range of negative and positive feelings, including inadequacy, discrimination, frustration, anger, exhaustion, stimulation and achievement. The negative feelings were caused by the stress experienced due to threats to their self-image and the fear of being appraised socially in an environment where they were not sure how to respond. Change, in itself, requires a person to adapt and this causes stress (Brooker et al. 2009:242-243).

The formation of support systems to aid their adaptation Expatriate life can be isolating and with this isolation comes depression. People want affirmation that what they are feeling or experiencing is not so unusual and that it will pass (Pascoe 2005). The participants sought and formed various support systems to help them cope with the cultural adjustment. These support systems were the participants' lifelines to successful adjustment as they journeyed through the phases of cultural adaptation. Areas of support came from colleagues and fellow South Africans. However, most of the participants identified family, friends and Christianity as their main areas of support. Myburgh et al. (2006:122) reported that the international students in their study also reported relying on support from home to alleviate their insecurity. They relied on modern technology to communicate regularly with their loved ones at home. Romas and Shama (2004:246) describe support systems as a set of social relationships with individuals who are helpful, provide positive assistance and who can provide protection from the negative consequences of stress. They identified four types of support systems, namely emotional, instrumental, informational and systems giving positive feedback. The participants reported all four types of support.

\section{Emotional experiences}

The emotions and feelings experienced by the participants were an integral part of the stages of cultural adjustment and are summed up by the following:

'In a nutshell, I have experienced happiness, sadness, depression, anger, frustration ... relief, guilt ... sometimes [you are] ecstatic when you achieve a little thing ... like (wow) I finally performed a

PowerPoint presentation ... and other times terrible sadness when you think of your loved ones left behind.'

Most of the participants felt that the 'sacrifice' of coming to the KSA was worth it, especially as far as financial gain was concerned. Many had managed to pay off debts and provide their families with much needed financial relief, which gave them a sense of achievement and pride and compensated for the negative emotions experienced. For a few participants, the 'sacrifice' and emotional pain of coming to the KSA had not been worth the financial gain. Two of the participants in the study did not complete their contracts. According to Romas and Sharma (2004:13), stress is largely caused by the individual's own perception of the stressor. The difference in climate and living conditions, loss of direct contact with their own family and the cultural differences were all external stressors that were perceived as very different from the life they were used to and were therefore experienced as threatening.

\section{Sub-theme 4: The participants' professional experiences}

Until recently, nursing training in the KSA has been inadequate. The hospitals thus rely primarily on international recruitment agencies to find qualified workers who can adapt to an international setting.
Relationships between nurses from different countries

A variety of needs assessments at the hospital have documented the stress of the cultural environment for all groups of expatriate nurses. Nurses report as much cultural pain in the adjustment to working with colleagues from different countries and different cultures as in working with Saudi patients. Although nursing is an established and universal subculture with its own set of values and norms, the participants discovered that nurses from other cultures brought with them differing approaches to nursing care, as well as different attitudes towards their colleagues.

\section{Communication in a multicultural professional environment}

The multinational nature of the hospital, with a workforce from approximately 31 different countries, creates a unique environment. The participants were faced with the challenge of communicating with patients and their family members (who could not speak English), colleagues, the multidisciplinary team, and friends. The main communication barriers identified by the participants were language differences and accents.

The participants said that they understood that they would have to adapt to the Arabic language. Although they sometimes learn a few words, it is usually not enough to communicate effectively. 'Knowing a smattering of a foreign language only allows one to make a "fluent fool" of oneself if the implicit meanings behind highly subtle linguistic symbols are not understood' (Pederson, in Ross \& Deverell 2004:27). The participants stated that although English was the language spoken at the hospital, even the nurses from English-speaking countries often did not use the language in the same way. The participants identified the different accents of the multinational workforce as a major barrier to communication. Not understanding what the person was saying, what a doctor was ordering, or what someone was asking affected their feelings of self-belief, self-worth and their morale. They experienced feelings of helplessness, frustration and stupidity and described these experiences as very painful. Myburgh et al. (2006:119) reported that the international students in their study reported similar frustrations with language use. They reported that, although English seems to be an international language, words used in different contexts seem to change meaning.

\section{Communication with patients and families}

When communicating with Arabic patients, it is necessary to understand the significant differences between Arabic and other languages. Moreover, it is necessary to understand that, in the KSA, most patients have a family member or 'sitter' with them. Consequently, communication with family, friends and sitters is an integral part of nursing Arabic patients.

The participants experienced certain aspects of both verbal and non-verbal communication to be a hindrance when interacting with Saudis. This is best described by a former hospital employee who wrote:

'My biggest frustration initially, was the loss of direct communication with my patients. My lack of spoken Arabic was a definite disadvantage. The language barrier often complicated the simplest task, turning it into a timely [time-consuming] and drawn out affair'.

The participants were immediately at a disadvantage when it came to non-verbal communication and object cues when nursing Saudi women. This was due to the cultural practice of women covering their head, face and body. Ross and Deverell (2004:29) describe non-verbal communication as meaning that the individual conveys using body movements. It usually conveys feelings, especially the intensity of an emotion. In a culture different from one's own, communication is already compromised, without the added barrier of not being able to observe the patient's head. 
The participants described not being able to use certain aspects of non-verbal communication, such as eye contact, touch, space, distance and intimacy, as hindering their interaction with patients. They considered these to be therapeutic and essential in establishing rapport with their patients, but soon realised that the use of touch was unwelcome. As a result, many participants experienced nursing to be 'so unrewarding' and 'emotionless'. The relationship between a nurse and a patient is a therapeutic alliance that can be used to offer information, reassurance and warmth (Kniesl \& Trigoboff 2009:206, 277). It is difficult to establish a relationship if the nurse cannot communicate directly with a client.

\section{The professional environment}

Hospital and general nursing orientation: During the threeday hospital orientation and an extensive eight-day general nursing orientation, the participants were able to establish support systems and friendships. Furthermore, they had a unit orientation of approximately ten days. The participants did not experience the same degree of support in the unit orientation as they had during the orientation programme. This gave rise to feelings of insecurity.

Many of the participants had preceptors who were enthusiastic, knowledgeable, encouraging and patient, which awarded them with an overall positive experience. However, a few had preceptors who were unwelcoming, unhelpful and critical and whose accents could not be understood - which left them with a negative experience that did not lend itself to an environment conducive to learning and adaptation. Feelings of frustration, isolation, worthlessness and inadequacy were experienced.

Ensuring competence and a level of knowledge: Having to complete the mandatory core competencies, courses and workshops was stressful for all of the participants. The required pass rate of $80 \%$ to $84 \%$ was an added stressor. Although many understood the rationale and realised the benefits of completing these requirements, it was apparent that they were angry with the agencies for not preparing them adequately. Additionally, having to work twelve-hour shifts as well as study and attend workshops/courses during their off-duty time led to feelings of exhaustion and added pressure.

Once the three-month probationary period was completed, the participants were more positive about the valuable educational opportunities they had encountered. Most recognised that the educational programmes enhanced their professional development. They expressed excitement and gratitude. This may indicate that the participants were not ready to learn on entering Saudi Arabia, but later realised the worth of the information and became receptive enough to engage in the learning process (Brooker et al. 2009:76).

The participants identified four areas in which they felt they had deficient knowledge or skills and these were:

- Pharmacology knowledge: During the first eight days, the participants were required to take a pharmacology examination. All agreed that the agency had prepared them and that they had received a pharmacology review package prior to departure. Nevertheless, many failed the examination on the first attempt. The participants attributed their 'struggle' in pharmacology to a deficiency in their basic training, the fact that there were no mandatory pharmacological updates for registered nurses after completion of their basic training in South Africa, and the fact that South African doctors normally work out doses/ drip rates for the nurses.

- Computer literacy: Participants had come to realise that they were expected to have basic computer skills to nurse in the KSA. Many felt very inadequate in this area and believed this was another shortcoming of their basic nursing training. Furthermore, they felt that the agencies had failed to inform them about this requirement.

- Basic physical assessment: Since the hospital is based on an American nursing system, a physical assessment of the patient has to be performed by the nurse within four hours (adults) and two hours (paediatrics) of coming on duty. Many participants had not been taught to perform an extensive physical assessment in their basic training - having to listen to the heart and respiratory sounds were particular areas with which they were unfamiliar. The participants who had completed a post-basic course in which primary healthcare assessments were included had more insight into the assessment.

- Basic cardiac life support (BCLS): It was mandatory for the participants to attend a BCLS course and to be certified in BCLS within a month of commencing employment. For the participants in the critical care areas, certification in advanced cardiac life support (ACLS) and paediatric advanced life support (PALS) were additional mandatory requirements.

Nursing care experiences: Whilst rendering nursing care to the Saudi population, the participants encountered the following positive and negative experiences:

Positive experiences:

- Being recognised as hard workers: The South African nursing corps had the reputation of being 'hard' and 'diligent' workers.

- Acceptance from the Saudi population and the caring work ethic: The participants were well received and accepted by the patients and their sitters. The caring aspect in nursing was seen as another of the South African nurses' strengths.

- Availability of equipment: The participants were delighted to have all the equipment needed to perform their routine nursing care efficiently.

Negative experiences:

- 'New bloke on the block' syndrome: The participants felt that they had to prove their competence and worth. The lack of acknowledgement of previous work experience created feelings of worthlessness and anger, and increased the stress they were already experiencing (Romas \& Sharma 2004:23).

- Inability to adhere to a nursing routine: The participants felt ineffective in performing their nursing duties because the patients/sitters determined when these duties should be executed.

- Nursing care given to males and females: The wards in the hospital contain a mixture of male and female patients. All rooms are private. A male cannot be a patient in a private room with a woman in the next room, hence a continual reassignment of rooms and patients. The male participant experienced frustration as he was prohibited from completing his assigned workload due to his services often being rejected by female patients/sitters and his being denied access to the rooms with women sitters. He experienced feelings of guilt, as his nursing duties had to be re-assigned to women nurses over and above their assignment.

- Ethics: In the KSA there is no legislation related to child care, such as a Nursing Act, Medical Act and Child Care Act. The Saudi Council for Health Professionals is in the very early stages of development. In the hospital the nurses sign and adhere to a code of professional conduct developed by the Gulf Cooperative Council (GCC) Health Ministers Executive Board in 2001. The participants were often exposed to situations, especially pertaining to the preservation of life, where decisions were made by physicians that went against their sense of ethical practice. Such experiences were unpleasant, had a significant effect on the participants and led to internal turmoil in all the participants.

- Patient advocacy: In the KSA, familism dictates that important decisions affecting the patient be made by the family and not by the individual alone. The participants experienced Saudi women as completely dependent on their male relatives to make decisions regarding their care. This resulted in feelings of disbelief and sadness for those Saudi women who had to undergo procedures deemed necessary by the male family member, but against the woman's will. The participants 
felt ineffective and helpless as patient advocates in these situations.

- Transcribing: 'Transcribing' is the term used when the nurse rewrites a physician's medication order from the latter's notes into the medication administration chart. It is entrenched in South African nurses throughout their training that transcribing medication is forbidden. The consequence of violating this rule can lead to disciplinary action by the South African Nursing Council (SANC). In the KSA, the hospital requires nurses to transcribe medications. The participants were not prepared for the moral dilemma in which they found themselves in this regard and experienced much anxiety and inner turmoil.

- Holistic care: Principles of holistic nursing care are incorporated into the basic training of South African nurses. The absence of holistic care was another negative nursing experience for the participants, as they continually encountered nurses and doctors who ignored or forgot the importance of this principle, namely nursing the patient holistically (with attention to the physical, spiritual and psycho-social aspects of care). Holistic care is treatment where the patient is treated as a whole - physiologically, psychologically and spiritually, and is not broken down into parts (Brooker et al. 2009:44).

Another negative experience relating to immigrating to and working in the KSA was the financial compensation for service. The hospital employees are categorised into zones according to nationality. The salary scale has forty steps, with the entry level depending on the zone from which one originates. Those from Zones 1 and 2 (North America) are the highest paid employees, closely followed by those from Zone 4 (the United Kingdom, some European countries, Australia and New Zealand). South Africans are in Zone 8 and therefore earn thousands of riyals less than nurses from the aforementioned countries. The participants found this to be an enormous bone of contention, as all staff on the same grades have the same job description and are expected to, and indeed do, perform the same duties. Moreover, the South Africans had not received a pay increase in the preceding six years, whereas nurses from many other zones received regular increases. The participants felt that this was discriminatory and experienced feelings of anger and demotivation. The rationale provided by the executive management was that South Africans came from an 'easy to get' market.

In some cases, the use of recruitment agencies also resulted in a negative experience. The particular areas in which the participants felt that the agencies had not been completely 'up front and honest' with them were related to salaries and the impact of a fluctuating exchange rate. Other areas in which the participants felt that the agencies had not prepared them adequately, were the general cultural environment and the extensive expectations regarding further education and competencies that were required during the orientation period.

\section{LIMITATIONS OF THE STUDY}

The first possible limitation of this study was that the nurses interviewed were all employed by the same hospital in the KSA. Secondly, limited literature was available on the research topic due to a lack of available data. Thirdly, the sample in the study had been in the KSA for only three to six months.

\section{RECOMMENDATIONS}

Based on the research findings, the following recommendations are made in relation to nursing research, education and practice.

\section{Nursing research}

Research projects into the following areas should be undertaken: - The coping strategies employed by family members, specifically the children, when a spouse or parent migrates to pursue a nursing career in the KSA.

- The experiences and adaptation of nurses who have lived and worked in the KSA for longer than six months.

- The personality profile of nurses who are, or are not, successful in adapting to living and working in the KSA.

- A comparative study of South African immigrant nurses working in other hospitals throughout the KSA.

\section{Ensuring emotional health and self-esteem}

South African nurses must ensure that they prepare themselves emotionally for staying in a hot, desert country where the cultural and religious practices are very different from those at home. Just familiarising oneself with the practices of a Muslim community is not enough; they need to ensure they are aware of, and knowledgeable in, the religious and environmental restrictions placed on women in the KSA (Rabat 2005:4).

There also needs to be an attempt to alleviate the intrapersonal relationship turmoil experienced by nurses in KSA. On arriving in the KSA, the nurses should be encouraged to join a support group that can facilitate supportive relationships with colleagues. Their family members, especially children, staying behind in South Africa should also be provided with the necessary support (Winkelman 2002:6).

\section{South African nursing education}

The following should be undertaken to improve South African nursing education:

- A review of the pharmacology and physical assessment components of the basic nursing diploma/degree courses because the South African nurses lacked knowledge in these areas.

- The institution of regular, mandatory pharmacological updates after basic nursing training for all registered nurses.

- The development of workshops/courses in basic computer skills and the inclusion of these in basic nursing training.

- A request to the SANC, as the Education and Training Quality Authority appointed for nursing, to inform the South African Qualifications Authority of the shortcomings in education identified by the nurses in the KSA and to suggest that international benchmarking be used for curriculum planning.

- The encouragement of the SANC to hasten the process and consider the information gleaned from this study when determining criteria for continuous education units and requirements for licensing and continuous professional development.

- The recommendation to the Saudi Council for Health Professionals that requirements be stipulated and completed before expatriate nurses are licensed to work in the KSA.

\section{Nursing practice recommendations}

In relation to nursing practice, the following are recommended:

- The integration of orientation guidelines into the orientation programmes presented by the various agencies that recruit nurses to the KSA, by focusing inter alia on: (1) creating awareness of the cultural aspects of living and working in Saudi Arabia, and (2) creating an awareness of the emotional and psychological turmoil experienced by South African Registered Nurses when living and working in the KSA and the coping mechanisms necessary for successful adaptation (Center for International Education 2005:2).

- The development of a self-assessment tool focusing on the psychological profile for nurses to complete before migrating to the KSA.

\section{CONCLUSION}

The reflections of these South African nurses living and working in the Kingdom of Saudi Arabia exposed the unique situation 
and circumstances they encountered. The researchers realised that the participants had to endure various difficult experiences while adapting to and coping in a new cultural, religious, physical, emotional and professional environment. It can be concluded from their experiences that successful adaptation seems to depend on their ability and willingness to embrace and engage in Saudi culture and their preparedness to change and develop personally and to view the challenges as opportunities for growth.

As a consequence of the perceived uniqueness of Saudi Arabian culture, Saudi enforcement of the Islamic faith and the lack of exposure of the outside world to this 'closed' country, the participants aptly concluded that nobody could be fully prepared for what awaits them in the Kingdom of Saudi Arabia.

\section{REFERENCES}

Andrews, M. \& Boyle, J., 1995, Transcultural concepts in nursing care, Lippincott, Philadelphia.

Antai-Ontong, D., 2008, Psychiatric nursing: Biological and behavioural concepts, 2nd edn., Delmar, New York.

Brooker, C., Waugh, A., van Rooyen, D. \& Jordan, P.J., 2009, Foundations of nursing practice - fundamentals of holistic care, Mosby Elsevier, Edinburgh.

Center for International Education, 2005, Cultural adjustment, University of California, viewed 12 December 2005, from http://.cie.uci.edu/world/shock.html

Crabtree, B.J. \& Miller, W.L., 1999, Doing qualitative research, 2nd edn., Sage, Thousand Oaks.

Creswell, J.W., 1994, Research design: Qualitative and quantitative approaches, Sage, California Thousand Oaks.

Democratic Nursing Organisation of South Africa, 1998, Ethical considerations in nursing, Van Schaik, Pretoria.

Donalek, J.G. \& Soldwisch, S., 2004, 'An introduction to qualitative research methods', Urologic Nursing 24(4), 354, 356.

Ham, A., 2004, Saudi Arabia, Lonely Planet Publications.

Hancock, C., 2001, 'Inaugural address', International Council for Nurses Congress, 14 June, ICN, Denmark.

Huda, 2005, Islamic New Year: What is the Hijrah calendar?, viewed 25 November 2005, from http://islam.about.com/ cs/calendar/a/hijrah_calendar.htm

International Council for Nurses, 2001, Position statement: Ethical nurse recruitment, ICN, Geneva.

International Council for Nurses, 2002, Career moves and migration: Critical questions, ICN, Geneva.

International Council for Nurses, 2003, 'International perspectives', International Nursing Review 50(1), 132-137.

Itano, N., 2002, 'South Africa sees health care crisis', Washington Times, 11 July, p. 1.

Kaplan, D., Brown, M. \& Meyer, B.P. 1999, Brain drain: New data, new options, viewed June 2004, from http://web.uct.ac.za/org/ sansa/
Kniesl, C.R. \& Trigoboff, E., 2009, Contemporary psychiatricmental health nursing, 2nd edn., Pearson Prentice Hall, Upper Saddle River.

Krefting, L., 1991, 'Rigor in qualitative research', American Journal of Occupational Therapy 45(3), 214-222.

Kvale, S., 1996, An introduction to qualitative research interviewing, Sage, London.

Mafalo, E., 2003, 'Shortage of nurses in SA: An impact to the health service and nursing profession', Nursing Update 26(5), 38-41.

Medi-Clinic, 2008, 'Indian nurses settle in South Africa', Nursing Update 32(4), 32-35.

Myburgh, C.P.H., Niehaus, L. \& Poggenpoel, M., 2006, 'International learners' experiences and coping mechanisms within a culturally diverse context', Education 123(1), 107129.

Naidoo, N., 2000, 'SA losing hundreds of nurses each year', Natal Witness, 24 May, p. 24.

Neuman, W.L., 1994, Social research methods: Qualitative and quantitative approaches, 2 nd edn., Allyn \& Bacon, Boston.

Pascoe, R., 2005, Support proves a lifeline in Shanghai, viewed 3 May 2005, from http://telegraph.co.uk/global/main/jhtml

Polit, D.F. \& Hungler, B.P., 1993, Essentials of nursing research. Methods, appraisal, and utilization, 3rd edn., JB Lippencott Company, Philadelphia.

Polit, D.F. \& Hungler, B.P., 1997, Essentials of nursing research. Methods, appraisal, and utilization, 4th edn., JB Lippencott Company, Philadelphia.

Rabat, M.V., 2005, Migration and religion in a globalized world, viewed 5 December 2005, from http://www.iom.int

Republic of South Africa, 2005, Annexure E to DPSA Circular 3 of 2005, Department of Health, Provincial Government, Western Cape, RSA.

Romas, J.A. \& Sharma, M., 2004, Practical stress management, 3rd edn., Pearson, San Francisco.

Ross, E. \& Deverell, A., 2004, Psychosocial approaches to health, illness and disability. A reader for health care professionals, Van Schaik, Pretoria.

Thompson, A., 2003, 'Where have all the nurses gone? Saturday Star, 22 February, p. 1.

Van der Merwe, T.D., 2003, 'The practice environment as an indicator of quality', paper presented at an International Symposium, Saudi German Hospital, Riyadh, March 2003.

Waughfield, C.G., 2002, Mental health concepts, 5th edn., Delmar, New York.

Wikipedia.org, 2005, Saudi Arabia, viewed 30 October 2005, from http://en.wikipedia.org/wiki/Saudi_Arabia

Winkelman, M., 2002, Culture shock and adaptation, Arizona State University, viewed 12 December 2005, from http:// www.asu.edu/clas/anthropology/bajaethnography shock/ htm 